OPEN ACCESS

Edited by:

Mathieu Lihoreau,

Centre National de la Recherche Scientifique (CNRS), France

Reviewed by:

Catherine Tait,

FR3743 Centre de Biologie Intégrative (CBI), France

Christopher Jernigan,

Cornell University, United States

*Correspondence:

Frank Azorsa

fazorsa@bu.edu

Specialty section:

This article was submitted to

Social Evolution

a section of the journal

Frontiers in Ecology and Evolution

Received: 29 October 2021 Accepted: 23 December 2021

Published: 15 February 2022

Citation:

Azorsa F, Muscedere ML and Traniello JFA (2022) Socioecology and Evolutionary Neurobiology of

Predatory Ants.

Front. Ecol. Evol. 9:804200.

doi: 10.3389/fevo.2021.804200

\section{Socioecology and Evolutionary Neurobiology of Predatory Ants}

\author{
Frank Azorsa ${ }^{1 *}$, Mario L. Muscedere ${ }^{1,2}$ and James F. A. Traniello ${ }^{1,3}$ \\ ${ }^{1}$ Department of Biology, Boston University, Boston, MA, United States, ${ }^{2}$ Undergraduate Program in Neuroscience, Boston \\ University, Boston, MA, United States, ${ }^{3}$ Graduate Program in Neuroscience, Boston University, Boston, MA, United States
}

Keywords: social brain, mandibles, mushroom body, cognition, navigation, chemical communication, brain scaling, sensory biology

Diet and social complexity are hypothesized to drive the evolution of the neuroarchitecture of the brain, but the relative impacts of foraging ecology and social organization have not been fully disentangled. Predatory ant species encompass generalists as well as specialists on remarkably narrow ranges of arthropod prey, and vary in strategy from solitary hunting to group raiding. Dietary differences and variation in individual or group predation appear to be correlated with the use of vision for navigation by solitary huntresses, the predominance of chemical signaling to organize group predation, and the structure, biomechanics, and sensorimotor control of the mandibles, and likely gustatory sensilla. Predatory ants provide the opportunity to separate the relative roles of diet and colony size and brain structure, and offer diverse novel systems to understand adaptive brain mosaicism and the neuronal regulation of predatory behavior. Here we discuss the socioecology of predatory ants and its influence on neuroanatomy.

\section{THE NEUROBIOLOGY OF PREDATION}

Neuroethological and molecular studies of visual, olfactory, auditory, pheromonal, electrical, and mechanoreceptive sensory systems have identified circuitry underpinning predatory behavior in diverse animal clades (Sillar et al., 2016). Star-nosed moles (Catania, 2011), electric fishes (Sukhum et al., 2018), and bats (Genzel et al., 2018) are renowned models. Predator sensory systems generally reflect foraging ecology. Many predatory insects, for example, have large eyes to detect and pursue moving prey through interceptive or ambush hunting strategies. Optic lobe neurons tuned to the motion of small moving objects regulate predatory behavior (Wardill et al., 2015, 2017; Fabian et al., 2018; Nicholas et al., 2018; Nityananda et al., 2018; Supple et al., 2020). Predators may also exhibit morphological and anatomical adaptations to prey type (Martinez et al., 2018) and/or group hunting strategies (Lang and Farine, 2017; Bastos et al., 2021). Predatory behavior in ants evolved independently multiple times in virtually all major subfamilies, including basal clades (Rabeling et al., 2008; Ward, 2014) and most predatory genera are sociobiologically and ecologically diverse (Keller and Peeters, 2020). Predatory ants often show striking differences in diet-usually linked to differences in mandible morphology, biomechanics, motor, olfactory and likely gustatory systemsand social organization. An evolutionary approach can integrate studies of foraging ecology, social structure, morphological evolution, neuroanatomy, and neurophysiology.

\section{MANDIBULAR MORPHOLOGY, SENSORY BIOLOGY, AND MOTOR CONTROL IN PREDATORY ANTS}

The morphology of the mandibles - the primary appendages ants use like tools to manipulate their environment and capture prey-varies widely across taxa. Most ants, including some extinct and extant predatory species, have triangular, shovel-shaped mandibles, but those of many predatory species have extreme morphologies (Figure 1) and biomechanical adaptations to specialized diets 
and prey-capture strategies (Brown and Wilson, 1959; Masuko, 1993, 2019, 2020; Dejean, 1997; Dejean and Dejean, 1998; Rabeling et al., 2012; Schmidt and Shattuck, 2014; Probst et al., 2015; Barden et al., 2020; Keller and Peeters, 2020). Predatory ant mandibles have associated neuronal mechanisms that, in some cases, control remarkably rapid closure. In trap-jaw ants, the mandibles can be cocked back (like a mousetrap) and then used to strike prey in as little as $0.33 \mathrm{~ms}$. Bite force and speed of depend on mandibular muscle biomechanics and properties of the motor neurons that innervate them (Gronenberg, 1996; Just and Gronenberg, 1999). Trap-jaw mandibles typically have sensory trigger hairs that respond to prey contact with a high-frequency burst of action potentials and project into the subesophageal zone (SEZ; Gronenberg et al., 1998a,b; Gronenberg and Riveros, 2009), a brain compartment involved in sensorimotor control of the mandibles, mouthparts, feeding behaviors, and gustation. The motor and chemosensory information transduced by sensilla is eventually processed by the mushroom bodies (MBs) a higherorder brain compartment strongly linked to learning, memory, and behavioral plasticity (Fahrbach, 2006; Gronenberg, 2008; Wright, 2016). Gronenberg et al. (1993) first described how the sensory-motor reflex of the trap-jaw strike of predatory Odontomachus workers is controlled by mechanoreceptor trigger hairs with large, rapidly conducting axons in what is likely a monosynaptic connection with motor neurons. Comparative analyses of trap-jaw mechanisms, which have evolved independently in multiple ant genera, reveal convergent biomechanical and neurobiological traits (Gronenberg, 1996; Larabee et al., 2017). Mandible closure velocity in trap-jaw ants appears to differ among species due to phylogeny, physiology, and prey specialization (Larabee et al., 2017, 2018; Gibson et al., 2018). The study of mandible morphology and neurobiology (motor control and sensory capabilities) of predatory ants may thus shed light on the relationships of diet, prey recognition, hunting and prey-capture strategies, and brain organization. Additionally, brain compartments associated with feeding (e.g., SEZ) may scale allometrically with prey-catching strategies, prey specialization, and colony size (Kamhi et al., 2017; Miroschnikow et al., 2020).

\section{DIET, SOCIALITY, AND BRAIN EVOLUTION}

Ecological brain theory hypothesizes that the behavioral and/or cognitive challenges of locating and processing food play a key role in brain evolution (Harvey et al., 1980; Goldman-Huertas et al., 2015; DeCasien et al., 2017; Lihoreau et al., 2019; Simons and Tibbetts, 2019). A high-quality (e.g., frugivorous) diet correlates with large brain size and expanded olfactory or visual systems in primates (Dunbar and Shultz, 2017; DeCasien and Higham, 2019). Social brain theory hypothesizes that brain size increases with group size and social complexity, due to cognitive challenges associated with increased conflict and cooperation (Dunbar and Shultz, 2017). Vertebrate societies are characterized by reproductive competition and social bonding, but eusocial insect workers are generally sterile. The applicability of social brain theory as developed for vertebrates to eusocial insects has thus been questioned (Lihoreau et al., 2012; Farris, 2016). Here we use the term social complexity as a working concept consistent with Anderson and McShea (2001): socially complex ants have large colony size, worker polymorphism and division of labor, and collective foraging strategies. Dornhaus et al. (2012) further discuss how collective organization may scale with colony size. Empirical studies of eusocial insect brain evolution indicate increased social complexity may increase or decrease worker brain size in larger colonies depending on reproductive conflict and division of labor (Jaffe and Perez, 1989; Wehner et al., 2007; Riveros et al., 2012; Muscedere et al., 2014; O’Donnell et al., 2015, 2018; Kamhi et al., 2016; Godfrey and Gronenberg, 2019; DeSilva et al., 2021). Brain structure is also known to change with worker age (Seid et al., 2008; Muscedere and Traniello, 2012) or task specializations that may develop in large colonies (AmadorVargas et al., 2015). Variation in diet, social organization, and behavioral polyphenisms in insects may be underpinned by neuroanatomical differentiation. Brain size in insects correlates with life history and diet (Farris and Roberts, 2005; Farris, 2008; Bouchebti and Arganda, 2020) and an increase in MB size, potentially supporting enhanced foraging-related navigation and memory (Sayol et al., 2020). At a cellular scale, the density of $\mathrm{MB}$ synaptic complexes (microglomeruli, MG) correlates with age, subcaste, task specialization or increase in behavioral repertoire (Groh and Rössler, 2011; Groh et al., 2014; Kamhi et al., 2017; Gordon and Traniello, 2018; Gordon et al., 2018), or requirements for higher-order processing involved in learning and memory (Li et al., 2017). Memory may be associated with a transient increase in MG density (Falibene et al., 2015). These latter studies are among the few suggesting a link between diet, social behavior, and brain evolution in insects. The relationship between diet and MB evolution remains poorly understood.

\section{PREDATORY ANTS AS MODELS OF BRAIN EVOLUTION}

Predatory behavior in ants evolved independently multiple times in virtually all major subfamilies, including basal clades. Predatory ants are widely distributed and sociobiologically and ecologically diverse. Workers are active predators, and species show striking differences in prey specialization, dietary breadth, and colony size (range from $<10$ workers [Thaumatomyrmex spp.] to 20 million [Dorylus wilverthi]), worker polymorphism, and division of labor. These ants thus have the potential to offer new insights into the relationship between social organization, diet, brain size, and mosaic structure. Army ants (Subfamily Dorylinae) are mass-foraging generalist or specialist predators that may form huge colonies of morphologically and behaviorally specialized workers (Kronauer, 2020; McKenzie et al., 2021). Predatory poneroid ants hunt alone or in groups and differ in diet and social complexity (Peeters, 1997; Ward, 2014; Hanisch et al., 2020). Solitary huntresses in some species broadly attack invertebrates whereas others specialize on termites, an energetically valuable clumped and sessile resource (Figure 1). The shift from randomly distributed prey to clumped prey involves changes in foraging behavior, resulting 



FIGURE 1 | Predatory behavior in ants. (A) Group foraging in Neoponera commutata, a specialized predator of termites, and (B) prey retrieval. (C) Daceton armigerum workers retrieving prey. (D) Odontomachus, a trap-jaw ant.

in an apparent decrease in use of vision (e.g., ommatidia size and/or number) for navigation by solitary workers to chemical signaling to organize group predation (Hölldobler and Traniello, 1980; Mill, 1984; Dejean and Lachaud, 2011; Jelley and Barden, 2021; Sosiak and Barden, 2021). These differences in hunting and prey-capture strategies, as well as the involvement of different sensory modalities in prey localization (Masuko, 1990; Gronenberg and Tautz, 1994; De la Mora et al., 2008), are associated with changes in behavioral demands for prey recognition, foraging communication, and foraging-task specialization (Schmidt and Overal, 2009) that will be reflected in volumetric changes in functionally specialized brain compartments. Other socioecological traits (activity pattern, nesting and foraging habits, foraging range, and prey distribution) are associated with morphological adaptations such as eye and antenna size, and sensilla type and density, and in turn linked with prey selection, diet, and brain mosaicism (Menzi, 1987; Polidori et al., 2012; Narendra et al., 2013; Ramirez-Esquivel et al., 2014; Bulova et al., 2016; Wittwer et al., 2017; Heinze et al., 2018; McKenzie et al., 2021). Prey olfactory detection and discrimination likely depend on the diversity of sensillae and receptors, and their neuronal projections into individual antennal lobe glomeruli that vary in size and number (Couto et al., 2005; van der Woude and Smid, 2016). These characteristics make predatory ants useful models to understand how dietary shifts may have shaped colony size and complexity, individual and group behavior, and brain and sensory system structure.

\section{COMPARATIVE AND PHYLOGENETIC ANALYSES}

Species that vary strongly in diet, predatory strategy, and social complexity can be compared to identify selective influences on brain mosaicism and synaptic architecture. For example, Neoponera laevigata is a specialized group-predator of termites: workers are polymorphic, colonies are relatively large $(\sim 1,500)$ and nomadic (Downing, 1978). In contrast, workers of the sister species $N$. apicalis are monomorphic generalist predators that forage solitarily and form small colonies ( $\sim 200$ workers; Schmidt and Shattuck, 2014). Other species that differ socioecologically include $N$. villosa (large colonies, generalist diet) and Leptogenys langi and Stigmatomma pallipes (small colonies, specialist diet). The influences of social organization and diet on brain compartment scaling and MG densities can thus be distinguished 
given that species have small or large colony size and generalist or specialist diets. Brain compartment volume variation of the [MBs], the optic [OL], the antennal lobes (AL; visual and olfactory information processing, respectively), and the SEZ can then be assessed to test the following hypotheses:

- If colony size and associated increases in social interactions, rather than diet, drive brain evolution, then species with large colonies with either generalist or specialist diets are hypothesized to have allometrically large MBs to process social information.

- If diet has a primary influence on brain evolution, then workers of prey-generalist species with both small and large colonies will have large MBs compared to specialist species (higher demands for navigational skills involving learning and memory [MB elaboration and increased MG density] in preygeneralist species; prey-specialist species depend on chemical signaling during foraging).

- Species with generalist diets that vary in behavioral and/or cognitive demands for prey recognition and navigation are predicted to have similar compartmental scaling in the OLs and ALs, and MG densities in large and small colonies (macroscopic and synaptic neuroanatomy are independent of colony size).

- Prey-specialist species will have reduced OL and increased AL size and a decrease in MG density in association with relative demands for processing visual (MB collar) and olfactory (MB lip) information, respectively.

- Prey-generalist species will have larger SEZ and a higher diversity and size of AL glomeruli (need to discriminate among prey).

- If the interaction of diet and colony size influence brain size evolution, then workers of prey-generalist species with large colonies will have allometrically large MBs (higher demands on sensory and behavioral functions).

- Neuroanatomical scaling and socioecology can be mapped phylogenetically to identify patterns of brain evolution. Detailed cellular analyses can be informed by and benefit from this broad analysis.

\section{REFERENCES}

Amador-Vargas, S., Gronenberg, W., Wcislo, W. T., and Mueller, U. (2015). Specialization and group size: brain and behavioural correlates of colony size in ants lacking morphological castes. Proc. Biol. Sci. 282:20142502. doi: $10.1098 / \mathrm{rspb} .2014 .2502$

Anderson, C., and McShea, D. W. (2001). Individual versus social complexity, with particular reference to ant colonies. Biol. Rev. Camb. Philos. Soc. 76, 211-237. doi: 10.1017/S1464793101005656

Barden, P., Perrichot, V., and Wang, B. (2020). Specialized predation drives aberrant morphological integration and diversity in the earliest ants. Curr. Biol. 30, 3818-3824.e4. doi: 10.1016/j.cub.2020.06.106

Bastos, D. A., Zuanon, J., Rapp Py-Daniel, L., and de Santana, C. D. (2021). Social predation in electric eels. Ecol. Evol. 11, 1088-1092. doi: 10.1002/ece3.7121

Bouchebti, S., and Arganda, S. (2020). Insect lifestyle and evolution of brain morphology. Curr. Opin. Insect. Sci. 42, 90-96. doi: 10.1016/j.cois.2020. 09.012

Brown, W. L., and Wilson, E. O. (1959). The evolution of the Dacetine ants. Q. Rev. Biol. 34, 278-294. doi: 10.1086/402828

\section{CONCLUSION}

Our understanding of the relationship between diet, sociality, brain size, compartmental scaling, synaptic architecture, and other neuroethological underpinnings of behavior can benefit from studies of predatory ants. Integrated sociobiological, ecological, morphological, neurobiological, transcriptomic, and genomic research is needed to understand the evolution of individual and group predatory strategies. Brain evolution can thus focus on the behavioral ecology of predation. Studies of morphological evolution can be integrated with sensory biology and motor control of the mandibles as well as the scaling of functionally specialized brain centers. The characterization of olfactory sensilla and their receptors on the mandibles, other mouthparts, and antennae, and investigation of AL glomeruli size and distribution are needed to understand mechanisms of gustation and their relationship with diet preference, prey identification, and prey-capture strategy. Additionally, we can infer whether gains and losses in neuroarchitecture are significantly associated with clades bearing particular individual worker and social traits and dietary habits.

\section{AUTHOR CONTRIBUTIONS}

FA, MM, and JT: conceived, wrote, and edited the manuscript. JT: secured funding. All authors contributed to editing the article and approved the submitted version.

\section{FUNDING}

This work was supported by NSF grants IOS 1354291 and IOS 1953393 to JT, and FONDECYT (372-2019) to FA and JT.

\section{ACKNOWLEDGMENTS}

We thank Dr. Wulfila Gronenberg for his expert comments and Dr. Isabella Muratore and Zach Coto for input while developing the manuscript. Dr. Mark Moffett kindly provided ant images.

Bulova, S., Purce, K., Khodak, P., Sulger, E., and O’Donnell, S. (2016). Into the black and back: the ecology of brain investment in Neotropical army ants (Formicidae: Dorylinae). Naturwissenschaften. 103:31. doi: 10.1007/s00114-016-1353-4

Catania, K. C. (2011). The sense of touch in the star-nosed mole: from mechanoreceptors to the brain. Philos. Trans. R. Soc. B Biol. Sci. 366, 3016-3025. doi: 10.1098/rstb.2011.0128

Couto, A., Alenius, M., and Dickson, B. J. (2005). Molecular, anatomical, and functional organization of the Drosophila olfactory system. Curr. Biol. 15, 1535-1547. doi: 10.1016/j.cub.2005.07.034

De la Mora, A., Pérez-Lachaud, G., and Lachaud, J. P. (2008). Mandible strike: the lethal weapon of Odontomachus opaciventris against small prey. Behav. Process. 78, 64-75. doi: 10.1016/j.beproc.2008.01.011

DeCasien, A. R., and Higham, J. P. (2019). Primate mosaic brain evolution reflects selection on sensory and cognitive specialization. Nat. Ecol. Evol. 3, 1483-1493. doi: 10.1038/s41559-019-0969-0

DeCasien, A. R., Williams, S. A., and Higham, J. P. (2017). Primate brain size is predicted by diet but not sociality. Nat. Ecol. Evol. 1:112. doi: 10.1038/s41559-017-0112 
Dejean, A. (1997). Distribution of colonies and prey specialization in the ponerine ant genus Leptogenys (Hymenoptera: Formicidae). Sociobiology 29, 293-300.

Dejean, A., and Dejean, A. (1998). How a ponerine ant acquired the most evolved mode of colony foundation. Insect. Soc. 45, 343-346. doi: $10.1007 /$ s000400050093

Dejean, A., and Lachaud, J. P. (2011). The hunting behavior of the African ponerine ant Pachycondyla pachyderma. Behav. Process. 86, 169-173. doi: 10.1016/j.beproc.2010.11.004

DeSilva, J. M., Traniello, J. F. A., Claxton, A., and Fannin, L. D. (2021). When and why did human brains decrease in size? A new change-point analysis and insights from brain evolution in ants. Front. Ecol. Evol. 9:742639. doi: $10.3389 /$ fevo.2021.742639

Dornhaus, A., Powell, S., and Bengston, S. (2012). Group size and its effects on collective organization. Annu. Rev. Entomol. 57, 123-141. doi: 10.1146/annurev-ento-120710-100604

Downing, H. (1978). Foraging and migratory behavior of the ponerine ant Termitopone laevigata (BA thesis). Northampton, MA: Smith College.

Dunbar, R. I. M., and Shultz, S. (2017). Why are there so many explanations for primate brain evolution? Philos. Trans. R. Soc. Lond. B Biol. Sci. 372:20160244. doi: 10.1098/rstb.2016.0244

Fabian, S. T., Sumner, M. E., Wardill, T. J., Rossoni, S., and Gonzalez-Bellido, P. T. (2018). Interception by two predatory fly species is explained by a proportional navigation feedback controller. J. R. Soc. Interface 15:20180466. doi: $10.1098 /$ rsif.2018.0466

Fahrbach, S. E. (2006). Structure of the mushroom bodies of the insect brain. Annu. Rev. Entomol. 51, 209-232. doi: 10.1146/annurev.ento.51.110104.150954

Falibene, A., Roces, F., and Rössler, W. (2015). Long-term avoidance memory formation is associated with a transient increase in mushroom body synaptic complexes in leaf-cutting ants. Front. Behav. Neurosci. 9:84. doi: 10.3389/fnbeh.2015.00084

Farris, S. M. (2008). Structural, functional and developmental convergence of the insect mushroom bodies with higher brain centers of vertebrates. Brain Behav. Evol. 72, 1-15. doi: 10.1159/000139457

Farris, S. M. (2016). Insect societies and the social brain. Curr. Opin. Insect. Sci. 15, 1-8. doi: 10.1016/j.cois.2016.01.010

Farris, S. M., and Roberts, N. S. (2005). Coevolution of generalist feeding ecologies and gyrencephalic mushroom bodies in insects. Proc. Natl. Acad. Sci. U.S.A. 102, 17394-17399. doi: 10.1073/pnas.0508430102

Genzel, D., Yovel, Y., and Yartsev, M. M. (2018). Neuroethology of bat navigation. Curr. Biol. 28:3198. doi: 10.1016/j.cub.2018.09.021

Gibson, J. C., Larabee, F. J., Touchard, A., Orivel, J., and Suarez, A. V. (2018). Mandible strike kinematics of the trap-jaw ant genus Anochetus Mayr (Hymenoptera: Formicidae). J. Zool. 306, 119-128. doi: 10.1111/jzo.12580

Godfrey, R. K., and Gronenberg, W. (2019). Brain evolution in social insects: advocating for the comparative approach. J. Comp. Physiol. A Neuroethol. Sens. Neural Behav. Physiol. 205, 13-32. doi: 10.1007/s00359-019-01315-7

Goldman-Huertas, B., Mitchell, R. F., Lapoint, R. T., Faucher, C. P., Hildebrand, J. G., and Whiteman, N. K. (2015). Evolution of herbivory in Drosophilidae linked to loss of behaviors, antennal responses, odorant receptors, and ancestral diet. Proc. Natl. Acad. Sci. U.S.A. 112, 3026-3031. doi: $10.1073 /$ pnas. 1424656112

Gordon, D. G., and Traniello, J. F. A. (2018). Synaptic organization and division of labor in the exceptionally polymorphic ant Pheidole rhea. Neurosci. Lett. 676, 46-50. doi: 10.1016/j.neulet.2018.04.001

Gordon, D. G., Zelaya, A., Ronk, K., and Traniello, J. F. A. (2018). Interspecific comparison of mushroom body synaptic complexes of dimorphic workers in the ant genus Pheidole. Neurosci. Lett. 662, 110-114. doi: 10.1016/j.neulet.2017.10.009

Groh, C., Kelber, C., Grübel, K., and Rössler, W. (2014). Density of mushroom body synaptic complexes limits intraspecies brain miniaturization in highly polymorphic leaf-cutting ant workers. Proc. Biol. Sci. 281:20140432. doi: 10.1098/rspb.2014.0432

Groh, C., and Rössler, W. (2011). Comparison of microglomerular structures in the mushroom body calyx of neopteran insects. Arthropod Struct. Dev. 40, 358-367. doi: 10.1016/j.asd.2010.12.002

Gronenberg, W. (1996). The trap-jaw mechanism in the dacetine ants Daceton armigerum and Strumigenys sp. J. Exp. Biol. 199, 2021-2033. doi: $10.1242 /$ jeb.199.9.2021
Gronenberg, W. (2008). Structure and function of ant (Hymenoptera: Formicidae) brains: strength in numbers. Myrmecol. News 11, 25-36.

Gronenberg, W., Brandão, C., Dietz, B. H., and Just, S. (1998a). Trap-jaws revisited: the mandible mechanism of the ant Acanthognathus. Physiol. Entomol. 23, 227-240. doi: 10.1046/j.1365-3032.1998.233081.x

Gronenberg, W., Hölldobler, B., and Alpert, G. D. (1998b). Jaws that snap: control of mandible movements in the ant Mystrium. J. Insect. Physiol. 44, 241-253. doi: 10.1016/S0022-1910(97)00145-5

Gronenberg, W., and Riveros, A. J. (2009). "Social brains and behavior - past and present," in Organization of Insect Societies: From Genome to Sociocomplexity, eds J. Gadau and J. Fewell (Cambridge: Harvard University Press), 377-401. doi: $10.2307 /$ j.ctv228vr0t.23

Gronenberg, W., and Tautz, J. (1994). The sensory basis for the trap-jaw mechanism in the ant Odontomachus bauri. J. Comp. Physiol. A 174, 49-60. doi: $10.1007 / \mathrm{BF} 00192005$

Gronenberg, W., Tautz, J., and Hölldobler, B. (1993). Fast trap jaws and giant neurons in the ant Odontomachus. Science 262, 561-563. doi: $10.1126 /$ science. 262.5133 .561

Hanisch, P. E., Drager, K., Yang, W. H., Tubaro, P. L., and Suarez, A. V. (2020). Intra- and interspecific variation in trophic ecology of 'predatory' ants in the subfamily Ponerinae. Ecol. Entomol. 45, 444-455. doi: 10.1111/een.12817

Harvey, P. H., Clutton-Brock, T. H., and Mace, G. M. (1980). Brain size and ecology in small mammals and primates. Proc. Natl. Acad. Sci. U.S.A. 77, 4387-4389. doi: 10.1073/pnas.77.7.4387

Heinze, S., Narendra, A., and Cheung, A. (2018). Principles of insect path integration. Curr. Biol. 28, R1043-R1058. doi: 10.1016/j.cub.2018.04.058

Hölldobler, B., and Traniello, J. F. A. (1980). The pygidial gland and chemical recruitment communication in Pachycondyla (=Termitopone) laevigata. J. Chem. Ecol. 6, 883-893. doi: 10.1007/BF00990472

Jaffe, K., and Perez, E. (1989). Comparative study of brain morphology in ants. Brain Behav. Evol. 33, 25-33. doi: 10.1159/000115895

Jelley, C., and Barden, P. (2021). Vision-linked traits associated with antenna size and foraging ecology across ants. Insect Syst. Divers. 5, 139-152. doi: 10.1093/isd/ixab020

Just, S., and Gronenberg, W. (1999). The control of mandible movements in the ant Odontomachus. J. Insect Physiol. 45, 231-240. doi: 10.1016/S0022-1910(98)00118-8

Kamhi, J. F., Gronenberg, W., Robson, S. K., and Traniello, J. F. A. (2016). Social complexity influences brain investment and neural operation costs in ants. Proc. Biol. Sci. 283:20161949. doi: 10.1098/rspb.2016.1949

Kamhi, J. F., Sandridge-Gresko, A., Walker, C., Robson, S. K. A., and Traniello, J. F. A. (2017). Worker brain development and colony organization in ants: does division of labor influence neuroplasticity? Dev. Neurobiol. 77,1072-1085. doi: $10.1002 /$ dneu.22496

Keller, R. A., and Peeters, C. (2020). "Poneroid ants," in Encyclopedia of Social Insects, ed C. Starr (Cham: Springer), 1-6. doi: 10.1007/978-3-319-90306-4_99-1

Kronauer, D. J. (2020). Army Ants: Nature's Ultimate Social Hunters. Cambridge: Harvard University Press. doi: 10.4159/9780674249417

Lang, S. D. J., and Farine, D. R. (2017). A multidimensional framework for studying social predation strategies. Nat. Ecol. Evol. 1, 1230-1239. doi: 10.1038/s41559-017-0245-0

Larabee, F. J., Gronenberg, W., and Suarez, A. V. (2017). Performance, morphology and control of power-amplified mandibles in the trap-jaw ant Myrmoteras (Hymenoptera: Formicidae). J. Exp. Biol. 220, 3062-3071. doi: $10.1242 /$ jeb. 156513

Larabee, F. J., Smith, A. A., and Suarez, A. V. (2018). Snap-jaw morphology is specialized for high-speed power amplification in the Dracula ant, Mystrium camillae. R. Soc. Open Sci. 5:181447. doi: 10.1098/rsos.181447

Li, L., MaBouDi, H., Egertová, M., Elphick, M. R., Chittka, L., and Perry, C. J. (2017). A possible structural correlate of learning performance on a colour discrimination task in the brain of the bumblebee. Proc. Biol. Sci. 284:20171323. doi: 10.1098/rspb.2017.1323

Lihoreau, M., Dubois, T., Gomez-Moracho, T., Kraus, S., Monchanin, C., and Pasquaretta, C. (2019). Putting the ecology back into insect cognition research. Adv. Insect Physiol. 57, 1-25. doi: 10.1016/bs.aiip.2019.08.002

Lihoreau, M., Latty, T., and Chittka, L. (2012). An exploration of the social brain hypothesis in insects. Front. Physiol. 3:442. doi: 10.3389/fphys.2012.00442 
Martinez, Q., Lebrun, R., Achmadi, A. S., Esselstyn, J. A., Evans, A. R., Haeney, L. R., et al. (2018). Convergent evolution of an extreme dietary specialisation, the olfactory system of worm-eating rodents. Sci. Rep. 8:17806. doi: 10.1038/s41598-018-35827-0

Masuko, K. (1990). Behavior and ecology of the enigmatic ant Leptanilla japonica Baroni Urbani (Hymenoptera: Formicidae: Leptanillinae). Insect Soc. 37, 31-57. doi: $10.1007 / \mathrm{BF} 02223813$

Masuko, K. (1993). Predation of centipedes by the primitive ant Amblyopone silvestrii. Bull. Assoc. Natl. Sci. Senshu 24, 35-43.

Masuko, K. (2019). Predation on non-spider arthropod eggs and colony bionomics of the ant Proceratium itoi (Hymenoptera: Formicidae). Ann. Entomol. Soc. Am. 112, 372-378. doi: 10.1093/aesa/saz012

Masuko, K. (2020). Colony composition, arthropod egg predation, and antennal structure of the ant Discothyrea sauteri (Hymenoptera: Formicidae). Asian Myrmecol. 12:e012002. doi: 10.20362/am.012002

McKenzie, S. K., Winston, M. E., Grewe, F., Vargas Asensio, G., RodríguezHernández, N., Rubin, B. E. R., et al. (2021). The genomic basis of army ant chemosensory adaptations. Mol. Ecol. 30, 6627-6641. doi: 10.1111/mec.16198

Menzi, U. (1987). Visual adaptation in nocturnal and diurnal ants. J. Comp. Physiol. 160, 11-21. doi: 10.1007/BF00613437

Mill, A. E. (1984). Predation by the ponerine ant Pachycondyla commutata on termites of the genus Syntermes in Amazonian rain forest. J. Nat. Hist. 18, 405-410. doi: 10.1080/00222938400770341

Miroschnikow, A., Schlegel, P., and Pankratz, M. J. (2020). Making feeding decisions in the Drosophila nervous system. Curr. Biol. 30, R831-R840. doi: 10.1016/j.cub.2020.06.036

Muscedere, M. L., Gronenberg, W., Moreau, C. S., and Traniello, J. F. A. (2014). Investment in higher order central processing regions is not constrained by brain size in social insects. Proc. Biol. Sci. 281:20140217. doi: $10.1098 /$ rspb.2014.0217

Muscedere, M. L., and Traniello, J. F. A. (2012). Division of labor in the hyperdiverse ant genus Pheidole is associated with distinct subcaste- and age-related patterns of worker brain organization. PLoS ONE 7:e31618. doi: 10.1371/journal.pone.0031618

Narendra, A., Gourmaud, S., and Zeil, J. (2013). Mapping the navigational knowledge of individually foraging ants, Myrmecia croslandi. Proc. Biol. Sci. 280:20130683. doi: 10.1098/rspb.2013.0683

Nicholas, S., Supple, J., Leibbrandt, R., Gonzalez-Bellido, P. T., and Nordström, K. (2018). Integration of small- and wide-field visual features in target-selective descending neurons of both predatory and nonpredatory Dipterans. J. Neurosci. 38, 10725-10733. doi: 10.1523/JNEUROSCI.1695-18.2018

Nityananda, V., Tarawneh, G., Henriksen, S., Umeton, D., Simmons, A., and Read, J. C. A. (2018). A novel form of stereo vision in the praying mantis. Curr. Biol. 28, 588-593.e4. doi: 10.1016/j.cub.2018.01.012

O’Donnell, S., Bulova, S. J., Barrett, M., and Fiocca, K. (2018). Size constraints and sensory adaptations affect mosaic brain evolution (paper waspsVespidae: Epiponini). Biol. J. Linn. Soc. 123, 302-310. doi: 10.1093/biolinnean/ blx 150

O’Donnell, S., Bulova, S. J., DeLeon, S., Khodak, P., Miller, S., and Sulger, E. (2015). Distributed cognition and social brains: reductions in mushroom body investment accompanied the origins of sociality in wasps (Hymenoptera: Vespidae). Proc. Biol. Sci. 282:20150791. doi: 10.1098/rspb.2015.0791

Peeters, C. (1997). “Morphologically 'primitive' ants: comparative review of social characters, and the importance of queen-worker dimorphism," in The Evolution of Social Behavior in Insects and Arachnids, eds Choe and Crespi (Cambridge: Cambridge University Press), 372-391. doi: 10.1017/CBO9780511721953.019

Polidori, C., Jorge García, A., and Nieves-Aldrey, J. L. (2012). Antennal sensillar equipment in closely related predatory wasp species (Hymenoptera: Philanthinae) hunting for different prey types. C. R. Biol. 335, 279-291. doi: 10.1016/j.crvi.2012.03.008

Probst, R. S., Guénard, B., and Boudinot, B. (2015). Toward understanding the predatory ant genus Myopias (Formicidae: Ponerinae), including a key to global species, male-based generic diagnosis, and new species description. Sociobiology 62, 192-212. doi: 10.13102/sociobiology.v62i2.192-212

Rabeling, C., Brown, J. M., and Verhaagh, M. (2008). Newly discovered sister lineage sheds light on early ant evolution. Proc. Natl. Acad. Sci. U.S.A. 105, 14913-14917. doi: 10.1073/pnas.0806187105
Rabeling, C., Verhaagh, M., and Garcia, M. V. B. (2012). Observations on the specialized predatory behavior of the pitchfork-mandibled Ponerine ant Thaumatomyrmex paludis (Hymenoptera: Formicidae). Breviora 533, 1-8. doi: 10.3099/MCZ3.1

Ramirez-Esquivel, F., Zeil, J., and Narendra, A. (2014). The antennal sensory array of the nocturnal bull ant Myrmecia pyriformis. Arthropod Struct. Dev. 43, 543-558. doi: 10.1016/j.asd.2014.07.004

Riveros, A. J., Seid, M. A., and Wcislo, W. T. (2012). Evolution of brain size in classbased societies of fungus-growing ants (Attini). Anim. Behav. 83, 1043-1049. doi: 10.1016/j.anbehav.2012.01.032

Sayol, F., Collado, M. A., Garcia-Porta, J., Seid, M. A., Gibbs, J., Agorreta, A., et al. (2020). Feeding specialization and longer generation time are associated with relatively larger brains in bees. Proc. Biol. Sci. 287:20200762. doi: $10.1098 / \mathrm{rspb} .2020 .0762$

Schmidt, C. A., and Shattuck, S. O. (2014). The Higher classification of the ant subfamily Ponerinae (Hymenoptera: Formicidae), with a review of Ponerine ecology and behavior. Zootaxa 3817, 1-242. doi: 10.11646/zootaxa.3817.1.1

Schmidt, J. O., and Overal, W. L. (2009). Venom and task specialization in Termitopone commutata (Hymenoptera: Formicidae). J. Hymenop. Res. $18,361-367$.

Seid, M. A., Goode, K., Li, C., and Traniello, J. F. A. (2008). Age- and subcasterelated patterns of serotonergic immunoreactivity in the optic lobes of the ant Pheidole dentata. Dev. Neurobiol. 68, 1325-1333. doi: 10.1002/dneu. 20663

Sillar, K. T., Picton, L. D., and Heitler, W. J. (2016). The Neuroethology of Predation and Escape. Wiley-Blackwell. doi: 10.1002/9781118527061

Simons, M., and Tibbetts, E. (2019). Insects as models for studying the evolution of animal cognition. Curr. Opin. Insect Sci. 34, 117-122. doi: 10.1016/j.cois.2019.05.009

Sosiak, C. E., and Barden, P. (2021). Multidimensional trait morphology predicts ecology across ant lineages. Funct. Ecol. 35, 139-152. doi: 10.1111/1365-2435.13697

Sukhum, K. V., Shen, J., and Carlson, B. A. (2018). Extreme enlargement of the cerebellum in a clade of teleost fishes that evolved a novel active sensory system. Curr. Biol. 28, 3857-3863.e3. doi: 10.1016/j.cub.2018.10.038

Supple, J. A., Pinto-Benito, D., Khoo, C., Wardill, T. J., Fabian, S. T., Liu, M., et al. (2020). Binocular encoding in the damselfly pre-motor target tracking system. Curr. Biol. 30, 645-656.e4. doi: 10.1016/j.cub.2019.12.031

van der Woude, E., and Smid, H. M. (2016). How to escape from Haller's rule: olfactory system complexity in small and large Trichogramma evanescens parasitic wasps. J. Comp. Neurol. 524, 1876-1891. doi: 10.1002/cne.23927

Ward, P. S. (2014). The phylogeny and evolution of ants. Annu. Rev. Ecol. Evol. Syst. 45, 23-43. doi: 10.1146/annurev-ecolsys-120213-091824

Wardill, T. J., Fabian, S. T., Pettigrew, A. C., Stavenga, D. G., Nordström, K., and Gonzalez-Bellido, P. T. (2017). A novel interception strategy in a miniature robber fly with extreme visual acuity. Curr. Biol. 27, 854-859. doi: 10.1016/j.cub.2017.01.050

Wardill, T. J., Knowles, K., Barlow, L., Tapia, G., Nordström, K., Olberg, R. M., et al. (2015). The killer fly hunger games: target size and speed predict decision to pursuit. Brain. Behav. Evol. 86, 28-37. doi: 10.1159/000435944

Wehner, R., Fukushi, T., and Isler, K. (2007). On being small: brain allometry in ants. Brain Behav. Evol. 69, 220-228. doi: 10.1159/000097057

Wittwer, B., Hefetz, A., Simon, T., Murphy, L. E. K., Elgar, M. A., Pierce, N. E., et al. (2017). Solitary bees reduce investment in communication compared with their social relatives. Proc. Natl. Acad. Sci. U.S.A. 114, 6569-6574. doi: $10.1073 /$ pnas.1620780114

Wright, G. A. (2016). To feed or not to feed: circuits involved in the control of feeding in insects. Curr. Opin. Neurobiol. 41, 87-91. doi: 10.1016/j.conb.2016.09.005

Conflict of Interest: The authors declare that the research was conducted in the absence of any commercial or financial relationships that could be construed as a potential conflict of interest.

Publisher's Note: All claims expressed in this article are solely those of the authors and do not necessarily represent those of their affiliated organizations, or those of the publisher, the editors and the reviewers. Any product that may be evaluated in 
this article, or claim that may be made by its manufacturer, is not guaranteed or endorsed by the publisher.

Copyright (๑) 2022 Azorsa, Muscedere and Traniello. This is an open-access article distributed under the terms of the Creative Commons Attribution License (CC BY).
The use, distribution or reproduction in other forums is permitted, provided the original author(s) and the copyright owner(s) are credited and that the original publication in this journal is cited, in accordance with accepted academic practice. No use, distribution or reproduction is permitted which does not comply with these terms. 